\title{
Research on Green Agricultural Products Closed Supply Chain Operation Mode and Strategy
}

\author{
Zuotie Wang \\ Harbin University of commerce, Harbin, Hei Longjiang Province \\ Suihua University,Suihua, Hei Longjiang Province \\ 6734496@qq.com
}

Keywords: Green agricultural products; closed supply chain; Operation mode; Development strategy

\begin{abstract}
Based on the actual situation of China's agricultural products market, this paper analyzes the meaning and characteristics of the closed supply chain of green agricultural products, and puts forward three types of green agricultural products closed-supply chain management model with agricultural leading enterprises, green agricultural products logistics centers and supermarkets as core enterprises, And proposed to reduce the enterprise cost of closed supply chain nodes through large-scale operation, and to establish green agricultural products "ID card" system to ensure the quality and safety of green agricultural products, and actively play the government role in the closed green supply chain of agricultural products to be the development strategy of green agricultural products closed supply chain.
\end{abstract}

\section{Introduction}

"The safety of food is the most important". With the rapid development of China's market economy, people's consumption level is rising, Income that people can disposed is increasing, China's agricultural market has realized a surplus from the shortage and the supply of agricultural products continued to increase, significantly increased varieties, with large supermarket enter the Chinese market, the supply of agricultural products more convenient. The selection criteria for agricultural products have shifted from quantitative security to quality security. ${ }^{[1]}$ Green, safe and healthy consumption concept has been deepened to the hearts of consumers; people pay more and more attention to the quality and safety of agricultural products.

In recent years, China's agricultural safety problems have been exposed, the event of multi-treasure fish, malachite green, triazolam milk powder and other events after another. The emergence of these agricultural safety incidents has aroused widespread concern about the quality of agricultural products, also shows problems and loopholes of China's agricultural supply chain system. In response to the quality and safety of agricultural products in China, the government, agricultural related enterprises and academia are actively discussing countermeasures, green agricultural products supply chain was put forward[2].

\section{The Meaning and Characteristics of Green Agricultural Products Closed Supply Chain}

The Meaning of the Green Agricultural Products Closed Supply Chain. Closed supply chain concept was first proposed by Professor Binglian Liu of the Nankai University of Modern Logistics Research Center .The main emphasis is the controllability of supply chain operations and the quality and safety of the products. The goal is to realize the safe and reliable supply of the products through management innovation of the supply chain. Closed supply chain of green agricultural products refers to the procurement of agricultural production materials, agricultural production, production processes and so on, from the purchase of agricultural implements and seeds, agricultural products, farming, picking, sorting and other origin of the initial processing flow to the hands of consumer. Provider of market access, multi-detection and information tracing, etc. to ensure the safety of green agricultural production. ${ }^{[3]}$ 
The Characteristics of Green Agricultural Products Closed Supply Chain. The government-led and closed supply chain node enterprise voluntary certification market access system is the green agricultural products closed supply chain should be multi-link objective certificated from planting, processing, sale of qualified implementation, because the authority, Mandatory and third-party of the government, and covers all the nodes in the supply chain and the safety of green agricultural products in all aspects, so green agricultural products through market access and on sales is safe and quality assurance. ${ }^{[4]}$ Green agricultural products that cannot meet the requirements of market access cannot enter the closed supply chain of green agricultural products.

The multi-level detection system of green agricultural products is an active supply-chain closure and agricultural safety detection mechanism, which is accompanied by the planting, processing, circulation and consumption of agricultural products. With the development of science and technology, detection of green agricultural products in the distribution channels is well, but there is lots of work to do in the green agricultural and green agricultural cultivation. In the sales process of green agricultural information cannot traces, because of there is no detection in the process of green agricultural cultivation and growth. ${ }^{[5]}$ Government and associations go to multi-level test from time to time, to ensure that consumers buy safe and reliable green agricultural products.

Information traceability is an effective way to monitor the safety of green agricultural products. From the procurement of green agricultural materials to the final consumption of the whole process of information traceability, to ensure the safety of green agricultural products, in the event of quality problems can also be traced through the information to find the whole closed supply chain in which nodes out of the problem. Green agricultural products to provide consumers with a closed supply chain bottom-up product traceability information, provide consumers green agricultural products growth, logistics and other full information support, in order to consumers ease to purchase green agricultural products ${ }^{[6]}$.

\section{Analysis of the Green Agricultural Products Closed Supply Chain Management Model}

Leading Agricultural Enterprises as the Core of the Closed Supply Chain Management. Because the scale of enterprises in green agricultural products closed supply chain is small, production and green security awareness is weak, the production of green agricultural products less secure. In the context of national policies support the development of agricultural cooperatives leading enterprises, agricultural cooperatives or leading enterprises integrated by many small and medium-sized green agricultural products are recognized by the market, which can rely on the preferential policies of the state, with strong capital, resources and management Agricultural cooperatives can be selected as the core enterprise of the closed supply chain of green agricultural products, so as to play a role in organizing the standardization of green agricultural product cultivation and strengthening the quality control, and establish a contractual cooperation relationship with a large number of green agricultural products farmers, From the source to ensure the quality of green agricultural products and security. As the core enterprise of the closed supply chain of green agricultural products, agricultural cooperatives rely on their industrial clustering advantages to formulate the enterprise selection criteria of closed supply chain, standardize the operation process of closed supply chain and establish a sound quality inspection standard and quality certification system of green agricultural products. Green agricultural cooperatives can establish a green agricultural product information tracking and control platform carry out the closed supply chain in the green agricultural products throughout the visualization and monitoring. Form the green brand through opening and traceability, gradually improve the value of green agricultural products and enhance the satisfaction of green agricultural products consumer.

Green Agricultural Logistics Center as the Core of the Closed Supply Chain Management. Realize the value of green agricultural products, we must overcome the space between the production and marketing and the time between supply and demand, which requires the help of green agricultural logistics center. As a core enterprise in the closed supply chain of green agricultural products, green agricultural products logistics center can play the role of distributing, storing and transporting information flow and capital flow in the closed supply chain, undertake the 
responsibility of quality and safety. Effectively reduce the investment of green agricultural products supply chain enterprises in the logistics, reduce the entire supply chain operational risk and improve market competitiveness. ${ }^{[7]}$ Because of the characteristics of perishable and metamorphic, green agricultural products in the transport, storage and distribution and other logistics links extremely stringent requirements, so need for specialized logistics facilities and equipment. If we want to guarantee the quality, safety, and professional logistics service of green agricultural products, professional third party agricultural products logistics center is necessary as the core of the closed supply chain .It can reduce the cost of green agricultural products and enhance the profitability of green agricultural products, green agricultural products are accepted by consumers. Logistics center of green agricultural products put the contract to closure the supply chain, with its professional and standardized advantages to achieve integrated logistics, green agricultural logistics center through advanced electronic information technology to achieve quality and safety monitoring, with the help of logistics standardization of green agricultural products "from the field to the table," the whole supply chain of standardized operation to ensure the quality and safety of green agricultural products.

Supermarkets as the Core of the Closed Supply Chain Management. With the rapid growth of supermarkets, supermarkets have become the most important sales channels of green agricultural products, also become an important part of the closed supply chain. In the model of supermarkets as the core of the closed supply chain, supermarkets can rely its strong financial advantages, international brand advantage and procurement channels, with green agricultural production enterprises, agricultural cooperatives, production bases, processing enterprises, through the contractual relationship to establish the benefit sharing, the risk sharing, through the effective communication with the green agricultural product consumers, from the closed supply chain terminal agricultural product cultivation and production, ensure the green agricultural product quality and safety, building the management model that supermarkets as the core of the green agricultural products closed supply chain. With government standards and industry standards develop and implement of more stringent green agricultural products suppliers access standards, to take government standards, industry standards and corporate standards, a combination of three strict and effective choice of suppliers, and use contracts and systems to strengthen the stability of closed supply chains. Supermarket or third-party professional testing businesses take multi-level quality and safety testing and tracking "from the farm to the table," through the complete information coding to achieve full traceability of green agricultural products, ensure quality and security of green agricultural products in the supermarket. ${ }^{[8]}$ As a node enterprises, supermarket directly facing the consumer in green agricultural products supply chain, it can collect demand information based on the green market, so that closed supply chain members of the enterprise reasonable planning and arrange their production activities to ensure that green agricultural production enterprises in accordance with the needs of consumers with the purpose of production, enhance the quality of green agricultural products, through the closed supply chain to achieve "from the farm to the table".

Analysis the Development Strategy of the Green Agricultural Products Supply Chain through Large-scale Operations to Reduce the Cost of Business in Closed Supply Chain. Face the strict market access system, multi-level detection mechanism and full information traceability technology of the closed supply chain of green agricultural products, if the individual business of the closed supply chain are separately produced and operated, the cost is very high, result the final price of green agricultural products is very expensive, unacceptable to consumers. Therefore, all the enterprises in green agricultural products closed supply chain should large-scale operation, through large-scale operations to reduce cultivation and production costs. Put the farmers join in the green agricultural cooperatives, promoting the development of green agricultural products leading enterprises to enhance the industrialization of agriculture and large-scale level, through this large-scale and industrial management approach, not only to meet the stringent requires of detection and traceability in green agricultural products supply chain, but also ensure the safety of green agricultural products and reduce the cost ${ }^{[9]}$. 
Establish "Identity Card" System of Green Agricultural Products. Establish green agricultural products "ID" system and information disclosure system to achieve full traceability of green agricultural information, so that it can clear the responsibility include agricultural supply enterprises, planting enterprises, processing enterprises, and third-party logistics and green agricultural products sales enterprises in closed supply chain enterprises. Government departments and green agricultural products related industry associations check green agricultural product quality and safety all aspects of the closed supply chain and increase the intensity of sampling testing, once discovered the products and events that do not meet the quality requirements of green agricultural products announce at the first time on the relevant platforms of the government and green agricultural products, severely punish and dealt. The green agricultural products related to consumer complaints were conducted on public information platform. Processing and publishing of green agricultural products safety warning.

Active the Role of Government in the Closed Supply Chain. The healthy development of the green agricultural products closed supply chain is inseparable from the overall planning and policy support of government. Government continue to improve the laws and regulate green agricultural products, protect the legitimate business of closed supply chain, promote fair competition in green agricultural products industry and improve the quality and safety of green agricultural products. To ensure the safety and quality of the green agricultural products from the source of the closed supply chain to the end consumers through the development of green agricultural production standards, packaging standards, storage and transportation standards. [10]In the system and publicity on the protection of green agricultural products in the market circulation, develop strict standards of green agricultural products, strict access to agricultural markets and inspection to ensure that does not meet the requirements of agricultural products cannot enter the green market and promote green agricultural products closed supply chain healthy and rapid development.

\section{Conclusion}

Implement access system, multi-level detection system and information retrospective system in green agricultural products market is the foundation to achieve green agricultural production, processing, trading, logistics and distribution in closed supply chain, to ensure the quality and safety of green agricultural products. At the same times, building a closed supply chain of green agricultural products with different types of enterprises as the core can create greater value for all nodes in the whole closed supply chain, improve the quality of green agricultural products, ensure the safety of green agricultural products and reduce the cost of green agricultural products.

\section{Acknowledgements}

Heilongjiang Provincial Education Department Project (2016): "Heilongjiang province agricultural product logistics development strategy research";

Heilongjiang Province Economic and Social Annual Project (2016): "The main grain producing areas of rural cooperative development research on Heilongjiang province, (project number: $16025) "$

Suihua Social Science Research Project: "Suihua agricultural products logistics service system (project number: SHSK2014048)";

Heilongjiang Province Arts and Science Planning Project: "Tourism product development and design of film and television in Heilongjiang province (project number: 2016D125)"

\section{References}

[1] Zhilun Jiao, China's urban food supply chain operation mode and its policy research, D.Tianjin: Nankai University, 2009.

[2] Mighell R.L., L.A. Jones, Vertical Coordination in Agriculture, R. USDA-ERS AGEC Report 19, 1963. 
[3] Changming Cheng, green agricultural products supply chain management model, J.Zhengzhou Institute of Aeronautical Industry Management. 2015 (2): 77-81.

[4] Duohong Wang, et al. Analysis on Operation of Closed Supply Chain of Green Agricultural Products Based on Logistics Center, J.Anhui Agricultural Sciences. 2010 (14): 7587-7590, 7594.

[5] Hong Huo, Yuchao Bu, Lingling Xu, Study on the Closed Supply Chain Construction of New Agricultural Materials under the View of Conflict Control,J.China Logistics \& Purchasing.2016 (7): $72-73$.

[6] Fuhua Huang, Min Zhou, closed supply chain environment of green agricultural common logistics model, J.Management World.2009 (10): 172-173.

[7] Weihua Liu,Yanping Liu,Binglian Liu, green agricultural product supply chain closed transformation method and practice research, J.soft science.2010 (4): 48-52.

[8] Weihua Liu, Jianhua Xiao,Zhilun Jiao, Typical Operation Mode and Cost Control of Agricultural Closed Supply Chain ,J.Soft Science.2009 (11): 58-63.

[9] Qian Zhang,Chongguang Li, agricultural product logistics development of supply chain management model and countermeasures, J.soft science. 2008 (1): 91-93.

[10] Xiao Han, Feng He, The Effect of Closed Supply Chain Operation Mode on Supply Chain Performance: A Case Study of 256 Leading Agricultural Enterprises,J.Finance and Economics.2014 (11): 92-101. 